\title{
Palimpsestos con Hélène Cixous: experimentos consigo mismo*
}

Fecha de recepción: 10 de marzo de 2017

Fecha de aprobación: 30 de junio de 2017

\section{Resumen}

Nuestra reflexión se interesa por la(s) lengua(s) habitadas por la escritora y filósofa Héléne Cixous a través de nuestra experiencia en sus clases y en la lectura continua de sus obras de carácter híbrido y abierto. Se trata de un diálogo que desarrollamos con su obra incluyendo nuestra propia experiencia con la escritura en forma de palimpsesto en el que tejemos sentidos y sensaciones de la palabra y sus resonancias.

Palabras clave: Cixous, literatura francesa, mundo árabe, escritura experimental.

Citar: Bejarano Hernández, A. (enero-junio de 2017). Palimpsestos con Hélène Cixous: experimentos consigo mismo. La Palabra, (30), 231 - 241. doi: https://doi. org/10.19053/01218530.n30.2017.6214

\author{
Alberto Bejarano Hernández \\ Doctor en Filosofía y estética, \\ de la Universidad París 8. Do- \\ cente-Investigador en literatura \\ comparada en el Instituto Caro \\ y Cuervo de Bogotá. Escritor. \\ otrasinquisiciones@hotmail.com \\ * Artículo de reflexión
}




\section{Palimpsests with Hélène Cixous: Experiments with Oneself}

\section{Abstract}

Our reflection is interested in the language(s) inhabited by the writer and philosopher Hélène Cixous through our experience in her classes and the continuous reading of her characteristically hibrid and open works. This dialogue with her work includes our own experience with writing in the form of a palimpsest, interwoven with senses and sensations of the word and its resonance.

Keywords: Cixous, French literature, Arab world, Experimental writing.

\section{Palimpsestes avec Hélène Cixous: expériences avec soi-même}

\section{Résumé}

Notre réflexion s'intéresse à (aux) la langue (s) que l'écrivain et philosophe Hélène Cixous habite, à partir de notre propre expérience dans ses cours et de la lecture de ses oeuvres hybrides et ouvertes. Il s'agit de construire un dialogue entre son oeuvre et notre propre expérience d'écriture sous forme de palimpseste où nous mettons en rapport des sens et des sensations de la parole avec des résonnances possibles.

Mots-clés: Cixous, littérature française, monde arabe, écriture expérimentale. 
Hélène Cixous no soy yo, es los que son contados en mi texto, porque sus vidas, sus penas, su fuerza exigen que resuene.

Un palimpsesto es un texto que pone en cuestión el régimen de la autoría, que confronta a la academia con sus formalismos y su imposibilidad para comprender lo contradictorio, lo paradójico, lo que genera sentidos complementarios. Podría decirse que el palimpsesto es una traducción de uno mismo como un-otro, siempre y cuando se entienda que el texto experimenta con la multiplicidad de sentidos de la literatura. Si partimos de la definición de palimpsesto que nos ofrece Genette (1989), veremos que el énfasis radica en el tipo de montaje que se proponga entre dos o más textos:

[...] la operación puede realizarse desde el principio sobre dos o más textos, cuyo montaje engendrará un nuevo texto, que aparecerá como una transformación de cada uno de ellos. Se pueden designar como lo hace Perec, estas técnicas de montaje con el término tradicional de contaminación (p. 62).
En nuestro caso, la estructura del texto experimental que compartimos responde a un llamado de la escritura en forma de palimpsesto, es decir, como operación de intensificación de fragmentos propios $\mathrm{y}$ ajenos que se enlazan en velos y desvelos del pensamiento y la vida. Podría sugerir que el uso de los fragmentos, por momentos en una deriva epistolar, apunta ante todo a confrontar al lector con varias velocidades de la escritura que sobrepasan el control "lógico" del autor y sus fantasmagorías. ${ }^{1}$

Dicha contaminación a la que alude Genette, siguiendo a Perec, nos sugiere que el texto está abierto a otros usos, que se puede intervenir la voz de otro haciéndola propia y a la vez, hacer de la voz propia un campo minado para sí mismo en el que viene a colarse otra voz. En este sentido, acudimos a Borges para desplegar la idea de contaminación, es decir, a reflexionar sobre la pregunta por quién escribe y de qué manera lo que escribimos habita en nuestras lecturas de manera espectral, como puede verse en varios de sus relatos, en especial en $\mathrm{El}_{\text {otro }}{ }^{2}$, donde un Borges joven dialoga con un Borges viejo. Todo se contamina. Críticos como Alazkari han estudiado estos montajes borgianos que apuntan a ver el palimpsesto como un proceso de transformación constante que nos confronta con la autoría. Para Alazkari (1984),

El contacto de dos textos puede darse como una relación de transformación. La naturaleza del palimpsesto del texto literario está sugerida por Borges en el párrafo final del "Inmortal", el texto que inscribe los múltiples destinos del inmortal es también un texto múltiple (p. 22).

Nuestro texto es pues un palimpsesto que merodea un llamado a/de la escritura de/desde/ hacia el pensamiento en un plano polifónico, buscando reflejar la forma como la escritora y filósofa francesa de origen argelino, Hélène Cixous, ha entrado en mi escritura y como yo he buscado entrar en la suya, como

\footnotetext{
1 Es lo que he venido desarrollando en los últimos años, por ejemplo al preguntarme por las sucesivas muertes del autor, desde Mallarmé: "Mallarmé no es singular, dirá Rancière, solo por sus ideas con respecto a la literatura y a la sociedad, sino por la forma como introduce transformaciones revolucionarias en la manera de escribir y leer un texto, en la indistinción entre géneros, y en la puesta en escena de la Vida como ejercicio experimental inagotable. La mirada política sobre/desde Mallarmé no se reduce a estudiar las ideas políticas del autor, sino a poner a resonar sus propuestas estéticas más allá de su tiempo, para generar nuevas configuraciones de lo sensible que sugieran otras formas de vida" (Bejarano, 2016, p. 133).

2 Ver Borges, “El otro", 2007.
} 
un pliegue de velos, corridos, secretos, temblorosos, ante todo desveladores de una manera de habitar en poesía-la-filosofía. Yo, como escritor envuelto en telas, como profesor de filosofía, desenvuelto en jeu-de-mots.

En la primera parte, me ocuparé de estudiar el concepto de escritura en Cixous como un des-velamiento progresivo de un nombrarse-como-un-otro. En la segunda parte, recurriré a lo prohibido, al uso/exposición de la primera persona quizá para acentuar un inquietante extrañamiento que me produce releer a Cixous y, a la vez, escribir de/con ella públicamente por primera vez, tras años de epístolas veladas.

$*$

Hélène Cixous nace en Orán, Argelia el 5 de junio de 1937. Llega a Francia en 1955. En 1968, se doctora en literatura inglesa sobre el exilio de Joyce. Fundadora de la Universidad de Vincennes (actual París 8) y del primer Doctorado en estudios femeninos en Francia. Desde 1984, escribe para el Théâtre $d u$ Soleil durante el camino, como ella mismo lo dice: "una escritura me encontró cuando era inencontrable a mí misma". (Cixous, 2006, p. 34).

Un primer elemento que destacamos de Cixous, es su definición de la literatura como ejercicio de transposición de sí mismo hacia otros en el que no se puede dejar de lado la condición singular de quien escribe, en su caso, una mujer que debió traducirse desde el origen de su familia, en árabe y en hebreo, al francés. Al igual que su amigo Derrida (2001), "Cixous habrá enternecido, quemado, mojado, luego descuartizado la vieja-nueva lengua francesa, la lengua bien amada, de la cual somos, los herederos, pero también los ladrones, los usurpadores, los espías, los agentes secretos, los colonizados colonizadores [...]”' (p. 48).

El punto de partida es entonces una huella que se disemina, una pregunta por el origen que no cesa, que no se completará nunca. De allí mi primer acercamiento hacia Cixous. Me interesaba indagar por la pregunta por uno mismo como un desconocido.

Una de las preguntas que ella siempre se ha planteado es: cómo se "llega a ser mujer", es decir, no sugiere una relación entre pensamiento y "lo" femenino como algo dado, como una evidencia que se constataría en una manera de pensar esperada o en un estilo habitual, o lo que Kant llamaba palabrería. La mujer no se puede limitar a un gusto por lo bello, como lo definía Kant (1997):

Un gusto rudo y sano, atenido siempre de cerca a este instinto, se preocu- pará poco en una mujer de los encantos del talle, del rostro, de los ojos, etcétera; como propiamente sólo tiene en cuenta el sexo, considera casi siempre vana palabrería las delicadezas de los demás. (p. 52).

No. El affaire de Cixous ha sido una revuelta permanente. Frente a la supuesta pasividad de lo femenino en la historia de la filosofía, ella ha irrumpido en la historia, sobre todo en su historia, con la lengua de Electra, la mujer que se enfrenta a los poderes establecidos para restaurar la justicia.

Para Cixous, el pensamiento en femenino tampoco está ligado a una cierta efusividad de los sentimientos. Lo femenino, pensando en Virginia Woolf (2009), sería más una forma intensiva de inquietarse por el mundo, preguntas que rozan el cuerpo: "adónde vagando voy?, musitó. ¿A lo largo de túneles barridos por el viento? ¿Dónde el ciego viento sopla? Y nada crece para recreo de la vista. Ni una rosa. ¿Para salir adónde?” (p. 147).

Lo que hay, dice Cixous, es una lengua de Electra, pura energía ligada además a lo animal, "acecho animal, ferocidad de un animal, ceguera animal", como Josefina la cantora de Kafka (2007), "ratona entre el pueblo de los ratones, que no es profeta, que muestra sus patas". (p. 
834). Hay mucho juego de ratones y ratas en la obra de Cixous, como en sus cartas a Marina Tsvetaeva, donde describe que sus cartas son como un lanzamiento de ratoncitos. En Cixous (1995), lo animal tiene que ver con acciones animales, con gestos: "mirada furibunda, voz que se esfuerza, escritura que se afana en hurgar, en desenterrar" ( $p$. 158).

En su diálogo con Kafka y Lispector, Cixous retoma también su idea de lo femenino como una anti-pasividad, como un fuego. Fuego es mujeres. Cixous (2006) siempre se pregunta ¿para qué sirve el cuerpo?, sobre todo con Clarice Lispector. Pero cuando se responde a sí misma, nos dice: "para ser yo misma mi hija cada día. Para la mujer, el cuerpo sirve supuestamente para la pasividad, a diferencia de para quienes está reservada la escritura, para los elegidos, y los hijos del libro" (p. 56). Para Cixous, la escritura rompe esa supuesta convención de lo femenino, como lo reservado a cierta belleza, como decía Kant.
En Cixous, hay una inquietud por el cuerpo, por la experiencia vivida que transmuta el pensamiento en acción animal. En la variedad de formas de entrar/ hacer una biografía, se evidencia el tipo de pensamiento que emerge. Esto puede verse en los diálogos intensos que sostuviera Cixous con Derrida, alrededor de la idea de mutación del pensamiento y de los velos, un ida y vuelta en/sobre la escritura que caracteriza la obra de estos dos pensadores, y en la que yo me he inmiscuido de una forma vital en los últimos trece años. ${ }^{3}$

El velo, nos recuerda Cixous, tiene varios sentidos desde su origen en latín, como vela de un barco y como tela que envuelve. Por su parte, Derrida recuerda el uso que hace Walter Benjamin de esta metáfora: "Ser dialéctico significa tener el viento de la historia en las velas. Las velas son los conceptos, pero no basta con disponer de velas. Lo que es decisivo es el arte de saber colocarlas" (Benjamin, citado en Derrida, 2001, p. 84). En otras palabras, velar apunta inevitablemente a de-velar. Tenemos aquí una primera defi- nición de traducción, de-velar, las ideas de otros. ${ }^{4}$ Uno mismo tiene que traducirse/desdoblarse para llegar a/escribir desde otro lugar, uno que no es tan distinto al origen como se pensaría. Uno no escribe para llegar a ser-otro, sino para volver a ser-otro. Yo-escribo para des-escribirme en rostros y pensamientos-de-mujer. Esta es mi confesión como palimpsesto.

Pensar en femenino, desde la lengua de Electra es lo que trato de hacer aquí, recordando que el velo es lo que no puede acallarse. No es pasividad. Por el contrario, es una libido infernal. Una de las definiciones en la que mejor puede captarse su fuerza, está en su relación con Esquilo en las coéforas: "Velos. Representación en las coéforas... la fuerza ambigua de Electra: una libido infernal. Nada puede acallar su voz. No hay justicia. Solo energía" (Cixous, 2006, p. 81).

Vamos ahora, querido(a) lector(a), a sumergirnos en otros

3 La traductora del libro, Velos, Mara Negrón, de Cixous y Derrida dice que "leer o traducir, leer y traducir es como cortar sesgadamente en un pliegue o en un lienzo" (Derrida, 2001, p. 23).

4 Esta búsqueda resuena mucho con una de las tesis que he tenido el gusto de dirigir en los últimos cinco años en la UPTC. Puede verse en el artículo de Andrea Vargas sobre Lispector: "En la búsqueda de la escritura como mirada miope, hay que forjar a un nadador íntegro, frágil y humilde, capaz de expandir sus maravillosos brazos de pulpo hacia la esencia velada, pero no para agarrar sino para desarrollar un tacto vibrátil que toca suavemente, acaricia y se aparta como un latido, justo a la manera de un ciego que comienza sus primeros contactos con el braille. Un recorrido que ve no viendo, que no agarra, que no toca del todo, que aguarda, que espera, que cuida, que besa y se deja besar apasionadamente por los bellos crustáceos, por los minúsculos organismos, especímenes, bichos, algas, y entrañas polimorfas que habitan el inmenso Hades, porque siempre hay algo que llama a la pequeña niña a levantar nuevamente la piedra del patio, a decidir cerrar los ojos y meter una de las manos mientras que la otra sostiene firmemente la redondez de la piedra, allí la niña con dedos de exploración se va a tientas." (Vargas, 2014, p. 149). 
velos. En un diálogo de contagio:

La escuché por primera vez en la Cité Universitaire de París, en el invierno de 2002. Yo, Alberto (por ahora) iba como asistente al que sería el último seminario de Derrida -justamente sobre lo animal-, y escuché nombrar allí, por primera vez, a Cixous. Por eso fui a sus charlas. Había una cita por cumplir, algo que yo ignoraba, una serie de velos me esperaban... un llamado. Yo era un recién venido y mi recibimiento en la estación de trenes de Saint Lazare, el 18 de septiembre de 2002 fue de revelamiento. Me tomaron por árabe, un par de mujeres "árabes", y me hablaron en su lengua. No solo eso, me confundieron con un primo suyo. ¿Qué hacer? Me dejé llevar, seguí su rumbo, entre señas $y$ balbuceos en francés. No habia más lenguas colonizadoras de por medio. Yo era como un sordo ávi- do de tocar esas palabras nuevas, o mejor, perdidas varios siglos atrás. Mohammed Fashahi me dijeron que me llamaba. Cómo no iba a creerles. ${ }^{5}$ En las clases de Cixous había varios árabes que hablaban entre sí en su lengua, me gustaba ver su caligrafia, la manera como tomaban apuntes y como dibujaban la cara de Cixous. Hablábamos a veces a la salida de las clases, ellos me preguntaban por la violencia en Colombia y yo por los conflictos del medio Oriente.

Necesito datar de nuevo estas historias, repetirme fechas y lugares, de ese-otro-yo, ya que como lo recuerda Derrida (2001): "datar es firmar. Y datar es también indicar el lugar de la firma" (p. 41). La presencia de Cixous no es solo un testimonio-de-vida, es una introspección filosófica sobre el problema de nombrar(se) como un-otro. ¿Qué significa el lugar de la firma? y, ¿qué ocurre cuando el que firma es-un-otro?
De allí la insistencia de Derrida en la "firma" cuando habla de Cixous. Y la insistencia de ella por datar y firmar:

Una voz de mujer llegó hasta mi desde muy lejos, como una voz de ciudad natal, me brindó conocimientos que antaño tuve, conocimientos íntimos, ingenuos, y sabios, antiguos $\mathrm{y}$ nuevos como el color amarillo y violeta de freshias $^{6}$ reencontrados, esta voz me resultaba desconocida, llegó a mi el doce de octubre de 1978, esta voz no me buscaba, escribía a nadie, a todas, a la escritura, en una lengua extranjera, no la hablo, pero mi corazón la comprende, y sus palabras silenciosas en todas las venas de mi vida se han traducido en sangre demente, en sangre alegría... una escritura llegó a paso de ángel: "he deambulado diez años por el desierto de los libros sin hallar una respuesta" (Cixous, 2006, p. 123).

$5 \quad$ "Al llegar a París la primera lengua que escuché no fue el francés sino el árabe. Supuse que era árabe, pero después entendí que era una variación del árabe que provenía de Palestina. Lengua de rosas, la llamó alguna vez Borges, en uno de esos poemas épicos que él componía con tanta justeza, pero en ese entonces no lo sabía. Fue así porque me hablaron en la estación de tren en árabe, repitiéndome varias veces un apellido, un nombre de familia que creían era el mío: Fashahi. Me dijeron, Mohamed, Mohamed, también somos Fashahi como tú. Me decían muchas cosas que yo no podía entender, aunque sentía que era esencial que lo supiera. Cuando después de intentar entendernos durante un largo rato en nuestro improvisado francés, al fin pude decirles que venía de Suramérica, se sorprendieron. Hablé como un poeta de Ventaquemada, Cajamarca, Santa Rosa de Osos, Villeta o el Alto del Trigo. Ellas me hablaron de ferrocarriles y de pueblos fantasmas, de animales fantásticos, de sueños que se repiten y tejen historias familiares, me hablaron de plagas y de pestes. Al final una de ellas, la del nombre más alegre, Dima, pronunció el nombre de Gabriel García Márquez y habló de Cien años de soledad en árabe... Muchos años después, alguien me dijo que lo que escuché esa noche fue algo que se escribía más o menos así: "تاملكلا هذه مضت نيوانع دجوي ال". Cuento del libro "Y la jaula se ha vuelto pájaro" de Alberto Bejarano, Ed Orbis, Bogotá, 2014.

$6 \quad$ Las freshias son flores que vegetan en el invierno, florecen en la primavera y permanecen en reposo durante la estación cálida. 
El palimpsesto irrumpe siempre como un texto que nos hace deambular sin respuestas entre textos, entre vidas, como cuando yo me dejaba llevar por lo que otros creían ver en mí, -un origen árabe- y volvía a las clases de Cixous a escucharla hablar de cómo la escritura nos hace hablar en una lengua extranjera (que es nuestra propia lengua, pero que desconocemos).

Cixous encuentra en la escritura un develamiento que le permite tocar, a tientas, una lengua extranjera en la cual puede dialogar con los fantasmas que la habitan desde tiempos arcaicos y que la definen de maneras insospechadas. Su deambular por la escritura, en especial por el género epistolar que tanto ha practicado a lo largo de su vida, es una inquietud libidinal. Aquí me desenvuelvo más yo.

El invierno del 2003 sería el último para Derrida. Yo apenas balbuceaba cartas y conocía de la mano de mi maestro, Patrice Vermeren, la mítica Cartoucherie, no lejos de las ruinas de lo que había sido el castillo de Vincennes donde había nacido París 8 en 1969. Alli funciona aún hoy el Théatre du Soleil, donde Cixous escribe obras de teatro desde 1984. Recuerdo haber visto una de sus obras, en 2004, "¿Qué es un refugiado? ¿Es usted un refugiado?”. He tenido que balancearme en mis propios archivos, cuadernos, hojas sueltas, borraduras, heridas, duelos, para encontrar el programa de mano de aquella obra: "De Ovidio a Mandelstam, los poetas son transfiguradores de penas en obras sublimes". Pero el 18 de septiembre de 2004 yo aún no conocía estas palabras, que no palabrerias de Cixous. Ni siquiera había oido hablar de ella en Bogotá. Así que cuando las leí, un par de semanas después de mi reencuentro con un tal Mohamed Fashahi adquirieron para mi un tono, un sabor, una reverberación que aún me acompaña... Confio en que la deriva de mis palabras no sea del todo críptica y pueda reflejar, al menos en parte, algo de la presencia porosa de Cixous en estos años de idas y vueltas, de ires $y$ venires. De alguna manera, mis palabras labran la ruta de una invocación, de un re-vela-miento de un pensamiento que se bifurca en mi propia escritura, pues la filosofia, por llamarlo aun así, que practica Cixous, - ¿practica?, no sería mejor tal vez llamarlo más directamente, habita-, está siempre marcada a fuego por su experiencia, en lo que ella misma ha denominado el llamado de la escritura. Me gustaría emplear aqui la palabra re-vela-miento, enfatizando en la suspensión que genera una forma de revelación que no conduce a una epifanía.
Cixous invoca a Electra, pero también se nombra (ah, el nombre, viejo problema), en masculino, como Aquiles. ¿Qué estatuto puede tener ese aparente giro, ese vela-miento, ese nombrarse como un doblemente otro...? La cuestión del nombre propio nos sumerge en una interrogación profunda, inestable, sobre el lugar y la posición del sujeto-que-se-piensa o cree-pensarse. En el caso de Cixous, nombrarse-en-masculino es una oportunidad para de-velarse de otra forma como mujer, como Macabea en La hora de la estrella de Clarice Lispector:

En los tiempos homéricos fui Aquiles. Sé por qué. Yo era el anti-virrey. Y la pasión. Tenía cóleras que complicaban la historia. Incordiaba a la jerarquía, al mando. Fui voz-grito. Agonía, palabra explotada, destrozada por el dolor y la cólera, pulverizando el discurso: así la han oído siempre desde la época en que la sociedad masculina empezó a marginarla de la parte central del escenario, a expulsarla, a despojarla. Desde Medea, desde Electra. (Cixous, 2006, p. 57).

Cixous-Electra se traduce como Aquiles. Ese nombrarse comoun-otro es una manera de incordiar para Cixous, es decir, de inquietar los supuestos lugares rígidos de enunciación de quien habla, su aparente identidad en 
este caso, como mujer. Al transfigurarse no solo en Electra, sino también en Aquiles, Cixous (2006) crea un espacio vacío, lleno de fantasmagorías, en el que puede hacerse vidente desde otros ojos, no-vidente desde sus propios ojos. En sus términos: "¿Saben los videntes que ven? ¿Saben los no-videntes que ven de otra manera? ¿Qué vemos? ¿Ven los ojos que ven? Lo unos ven y no saben que ven. Tienen ojos y no ven que no-ven" (p. 32).

En mi caso, el seudónimo que más he usado es Aquiles Cuervo, llegué incluso a publicar mi primer libro de cuentos con ese nombre y luego el segundo co-firmando con él. He llegado a hacer lecturas públicas presentándome no solamente con el nombre de Aquiles, sino jugando con una identidad múltiple, camaleónica, de acuerdo al lugar y a la ocasión. Quizá algún día pueda transfigurarme en Electra...

Recuerdo que por esos
años, cuando hacía mi
tesis de Maestría sobre la
correspondencia de Spino-
za y otros filósofos, apare-
ció con fuerza Cixous, su
llamado a la escritura, la

pregunta ya no solo por quien escribe, es decir, un paso más allá de lo impersonal, si es que algo así es posible. Era una inquietud por el yo -que-se-escribe-siendo-escrito, una herida, algo en el cuerpo que desgarra y devoile (no en el doble sentido que surge en español, como desvelo nocturno), algo, una estela, un silencio que no se llena cuando se escribe. Hablaba de mí mismo sin saberlo. ${ }^{7}$

\footnotetext{
"Es una tarde del final del verano de 2004. Estoy sentado con un grupo de amigos franceses, africanos, tailandeses, argentinos y colombianos en el jardín, la pelouse de la Fondation Deutsch de la Meurthe de la Ciudad Universitaria en París. Tengo 20 años y debo tomar una decisión. La Ciudad Universitaria es un inmenso campus al sur de París donde llegan estudiantes de todo el mundo a descubrir otras culturas y a compartir las suyas. Uno pasa semanas enteras sin salir de ahí, sin cruzar la frontera del Boulevard Jourdan que da al parque Montsouris, y a la París-que-no-se-acaba-nunca. Entre las bibliotecas, los restaurantes, los jardines, las canchas, y las fiestas se le va a uno el tiempo sin darse cuenta. Uno se enamora en otras lenguas y se olvida por momentos de quien está al otro lado del mar. Hacer el amor y no la guerra, es la consigna de la Cité U. Uno hace lo que puede para cumplirlo, de la casa del Brasil, a la de Marruecos, pasando por la del este de Asia y la canadiense. Cada quien trae su traje y su dialecto. Cada cual le pone un ritmo a su tumbao, y si no lo tiene, se lo inventa. El único problema es que no se puede estar más de tres años aquí. Esta tarde es la última de mi temporada. Se que me iré de la Cité, pero no se a dónde. Tengo dos caminos abiertos: vuelvo a Colombia a ser un eterno profesor universitario o me quedo en Europa haciendo algo completamente distinto. Llevo tres años en París como estudiante de filosofía, con una pequeña beca con la que apenas puedo pagar el cuarto. Hago una tesis sobre Spinoza, escarbo en su correspondencia todos sus sueños, misterios y silencios. Pulo unos lentes distintos a los suyos, mi sangre morisca tira para otro lado. Paso mucha hambre. A veces no tengo ni para un ticket de metro ni para un café de treinta centavos en una máquina. En los inviernos me arrastro de biblioteca en biblioteca, de museo en museo, con los labios partidos, los abrigos desteñidos y los guantes remendados. No me quejo. Soy como un monje, sin fumar ni beber. En el último año he bajado quince kilos, estoy tan enflaquecido que mis amigos -Eugenia, Claudia, David, Salem, Fernando, Magalie, María Fernanda, Álvaro, Marcela, Paum, Tanya- hacen lo posible por invitarme a comer y me dejan mercados disimuladamente en mi cuarto: arroz basmati, calados, café, sopas en conserva, chocolates amargos, mate, couscous, garbanzos, cacahuetes. Nada perecedero. No he querido trabajar en ninguno de los oficios que hacen los estudiantes: cuidar niños, dar clases de español, repartir volantes, meseriar... prefiero pasarme las tardes en los cines del quartier latin y las noches blancas leyendo novelas (sobre todo de Bolaño) y escribiendo poemas y diarios, pero el último año ha sido distinto. Mis amigos me organizaron una fiesta de cumpleaños el 3 de enero e Ismael, de Camerún, propuso que yo diera una clase de salsa para no-iniciados. Nunca había hecho algo así. Uno baila como lo siente, sin tomar clases y se deja llevar por el ritmo, por el bam bam ki ri ri bam bam. En Bogotá, bailaba en un bar que se llamaba El Antifaz. Al principio dudo, no sabría cómo enseñar algo que aprendí mirando a mi mamá desde niño en los bares de salsa de Bogotá. Ella era una bailarina muy famosa, todos la recuerdan incluso hoy, por su belleza y su cadencia. Yo me acuerdo de estar mirándola, en la euforia de sus noches, viendo cómo se enamoraban de ella y ella solo bailaba y bailaba. Crecí en esos clubes siendo el "hijo de Libia". Antes de irme de Bogotá, me llamaban todavía así y a cualquier lugar que llegaba tenía que cargar con ser la sombra de mi madre. El pequeño Alberto. El Niño, el retoño de la flor, como decía una poeta. Hasta cuando me regalaban un mojito me decían, "salud... por tu mamá". Finalmente me decido y la noche de mi cumpleaños doy mi primera clase. Arranco con la canción de Joe Arroyo, "Pal bailador": "Y un pasito tun tun y otro pasito tun tun". El Joe es puro fuego en la mente, ¿o no? "Pa todos aquellos que no sabían cómo baila el son, pal bailador, camisas pal bailador". Ah, la vida está hecha de retazos que se mezclan, que se pegan a la piel unos con otros. A lo mejor, uno siempre cuenta la misma historia mil y una noches". Del cuento inédito "Pal bailador" de Alberto Bejarano que primero fue un performance dirigido por la artista francesa Fanny de Chaillé en Bogotá en Experimenta Sur, septiembre de 2015.
} 
ALBERTO: París, noviembre 15 de 2002. Madame Cixous, no me atrevo a llamarte

Hélène-te decía, en aquel primer invierno de mi vida-, esa experiencia de habitar las lenguas como una intrusa, como la no-llamada, como la ladrona dices tú, resuena en mi por mi propia experiencia, pues mi vecina en las residencias universitarias canta cada madrugada un murmullo árabe, como unas letanías -si hubiera podido grabarla-, a mí me sonaba árabe, como si supiera realmente a lo que "eso" suena, pues ella es palestina, pero de origen armenio. Yo asisto los jueves a tus charlas sobre lengua y pensamiento, pero desvivo en esa voz de las madrugadas... hasta ahora puedo ver la conexión.

Imagino ahora su hipotética respuesta, como salida de una Obra de teatro de Marguerite Duras, digamos, Cinema Edén:

\section{HÈLENE:}

En cuanto empieza a hablar se le puede enseñar, al mismo tiempo que su nombre, que su región es negra: eres África y, por tanto, eres negra. Tu continente es negro. El negro es peligroso. En el negro no ves nada, tienes miedo... pero no es negro ni inex- plorable: aún está inexplorado porque nos han hecho creer que era demasiado negro para ser explorable. (Cixous, 2006, p. 80).

ALBERTO: Madame, tanto Derrida como tú nos han enseñado el arte de una nueva forma de pensamiento que se conjuga de formas misteriosas y a veces secretas con nuestras biografías. Es lo que Derrida (2001) llamaba otobiografía que no es simplemente una variación del yo, sino un llamado animal que surfea la razón... una biografía de uno mismo a partir de lo que dicen los otros: "Un discurso acerca de la vida-la-muerte debe ocupar cierto espacio entre el logos y el gramma, la analogía y el programa... debe sin duda trabajar también entre lo biológico, lo tanatológico y lo tanatográfico" (p. 30).

ALBERTO: Claro, el invierno del 2002... Yo le escribía cartas a dos mujeres (bueno, realmente eran tres, a la otra, la llamaba Electra), a la mujer palestina, que aún no me atrevía a ver a los ojos ni mucho menos a hablarle cuando me la encontraba en los jardines de invierno desolados, prohibidos, y a ti, Cixous, a través de ella. A veces lo hacía en francés y un par de veces estuve a punto de entregarte mi rudimentaria lettre en los salones de la Fundación Heinrich Heine, pero nunca me atreví. ¿Qué te decía, qué me decia? Te hablaba en francés del efecto que me producian las voces que no entendía, pero que podía sentir. El doble sentido de entendre en francés. Había algo que no era de rosas, como me decía Borges al otro lado de la puerta. Si tú, Cixous eres una juiffemme... ¿Quién más eres tú?

\section{HÈLENE:}

Mi padre sefardita -España, Marruecos, Argelia-, mi madre askhenazí -Austria, Hungría, Checoslovaquia (su padre)+ Alemania + (su madre) pasando casualmente por un París efímero"... y luego, "efecto de diáspora. No tengo lengua legítima. En alemán canto, en inglés me disfrazo, en francés robo, soy ladrona. (Cixous, 2006, p. 79).

AQUILES: $Y$, la otra mujer, ¿que sería? Armenia y Palestina, la historia revuelta de dos grandes genocidios, ignorados, sepultados. Con esta historia, olvidando en ese momento a Cixous, escribi un cuento que titulé "una voz/una soledad". Ahora, resuenan a posteriori estas palabras tuyas que si invoqué en el título de mi libro, Y la jaula se ha vuelto pájaro (Pizarnik, esa otra mujer de desvelamientos), co-escrito además con alguien que se hace llamar 
Aquiles... como tú. ${ }^{8}$ ¿Quién más eres tú?

HÈLENE:

He sido la Pentesilea de Kleist, no sin ser Aquiles, he sido Antonio para Cleopatra y Cleopatra para Antonio... he sido santa Teresa de Ávila, aquella loca que sabía más que todos los hombres. Y que sabía a fuerza de querer convertirse en pájaro... además he sido siempre un pájaro. Un poco buitre, un poco águila: he mirado al sol de frente. (Cixous, 2006, p. 134).

La pregunta por quién se es (o se cree ser), siempre trae oculta la pregunta por quién no se es, no se ha sido o nunca se será. Esto es lo que he aprendido en mis palimpsestos. Esto proba- blemente se lo escribe Aquiles a Alberto. Me despido porque va empezar un partido de Messi...

\section{Para (no) terminar}

En este deambular de la escritura y el pensamiento, donde la ficción no habita en la ficción como yo lo creía ciegamente en Borges antes de Cixous-, donde la filosofía se revela contra la pasividad en voces que irrumpen como un velo desgarrado(r), donde la voz del escritor usurpa el discurso crítico, y también lo femenino a lo masculino, lo animal a lo humano, lo ambivalente a lo identitario, me he venido re-encontrando con algo que resuena en mí desde que supe que también me llamaba Mohamed Fashahi... gracias a Cixous, $c i$ seaux... (ese es el llamado de la escritura, jser llamado!). La pregunta decisiva de Cixous es: “¿dónde tiene lugar la diferencia en la escritura? Si existe diferencia radica en los modos del gasto, de la valoración de lo propio, en la manera de pensar lo no-mismo". (Cixous, 2006, p. 22).

Eso sería el palimpsesto, una manera de pensar lo no-mismo, en mi caso a partir de la intrusión de/el montaje de textos de otros con mis propios recuerdos metamorfoseados por los archivos sucesivos, por las relecturas literarias de mí mismo que han venido aconteciendo desde entonces. Yo-es-otro es una invocación a uno mismo como un palimpsesto.

Quince años han transcurrido desde aquel devenir Aquiles-Fashahi, estudiante en un país extranjero para regresar y ser profesor en el propio, siguiendo siempre el llamado de la escritura, de ida y vuelta, entre Aquiles y Alberto.

\section{Referencias}

Alazraki, J. (1984). El texto como palimpsesto: lectura intertextual de Borges. Hispanic review, 52(3), 281-302. doi: 10.2307/474142.Bejarano, A. (2014). Y la jaula se ha vuelto pájaro. Bogotá: Orbis.

Bejarano, A. (2016). Poéticas del intruso. Jacques Rancière, lector de Mallarmé. La Palabra, (29), 129137.

Borges, J.L. (2007). Obras completas. Buenos Aires: Emecé.

$8 \quad$ Cómo perder de vista que Kafka (2007) decía en un aforismo, “La jaula salió en busca de un pájaro” (p. 945). 
Cixous, H. (2006). La llegada a la escritura. Buenos Aires: Amorrortu.

Cixous, H. (1995). La balsa de la medusa. Barcelona: Anthropos.

Derrida, J. (2001). Cixous, Hélène. Velos. México: Siglo XXI.

Genette, G. (1989). Palimpsestos. Madrid: Taurus.

Kafka, F. (2007). Obras completas. Madrid: Galaxia.

Kant, E. (1997). Lo bello y lo súblime. Madrid: Espasa.

Vargas Quiroz, P. (2014). Me gustan tus ojos miopes (O del diálogo con Hélène Cixous para llevar al cuerpo, a la literatura, a la vida). La Palabra, (25), 143-156.

Woolf, V. (2009). Entre actos. Barcelona: Random House. 